\title{
Physical and Mechanical Properties of Selected Common Beans (Phaseolus vulgaris L.) Cultivated in Tanzania
}

\author{
Addi Atuswilye Sanga Palilo $\mathbb{D}^{1},{ }^{1}$ BashiraAlli Majaja, ${ }^{2}$ and Baraka Kichonge $\mathbb{D}^{3}$ \\ ${ }^{1}$ College of Engineering and Technology (CET), Mbeya University of Science and Technology (MUST), Mbeya, Tanzania \\ ${ }^{2}$ College of Engineering and Technology (CoET), University of Dar es Salaam (UDSM), Dar es Salaam, Tanzania \\ ${ }^{3}$ Mechanical Engineering Department, Arusha Technical College (ATC), Arusha, Tanzania \\ Correspondence should be addressed to Baraka Kichonge; kichonge@yahoo.com
}

Received 16 May 2018; Accepted 30 July 2018; Published 12 August 2018

Academic Editor: Navin K. Rastogi

Copyright (C) 2018 Addi Atuswilye Sanga Palilo et al. This is an open access article distributed under the Creative Commons Attribution License, which permits unrestricted use, distribution, and reproduction in any medium, provided the original work is properly cited.

\begin{abstract}
The physical and mechanical properties of foods are important, if not essential, in the design of suitable systems, machines, and structures for planting, harvesting, handling and processing of agro-products. Phaseolus vulgaris L. is a popular legume species that play an important role in human diet and among easily available sources of plant protein. However, despite its important roles, there is a lack of information on the physical and mechanical properties of common beans cultivated in Tanzania. The objective of this study was therefore focused on experimental determination of physical and mechanical properties for Uyole-96, Kablanketi, and Wanja, common beans cultivars grown in the Southern Highlands of Tanzania. Experimental results showed that the average length, width, and thickness were $19.96 \mathrm{~mm}, 8.97 \mathrm{~mm}$, and $7.6 \mathrm{~mm}$ at a moisture content of $17.15 \%$ dry basis (db.), $13.92 \% \mathrm{db}$., and $14.64 \% \mathrm{db}$. for Uyole-96, Kablanketi, and Wanja, respectively. The results further show that the average mean diameters $\left(D_{a}\right)$ were $10.93,9.35$, and $9.55 \mathrm{~mm}$ for Uyole-96, Kablanketi, and Wanja, respectively. The geometric mean diameters $\left(\mathrm{D}_{\mathrm{g}}\right)$ were $9.66,8.35$, and $8.80 \mathrm{~mm}$ for Uyole-96, Kablanketi, and Wanja, respectively, whereas sphericity was found to be 53, 64, and 58\% for the same types of beans. Repose angle measuremnts were experimentally determined as 40, 36, and 35 degrees for Uyole-96, Kablanketi, and Wanja, respectively. Weight for apparent density analysis was $709.27,686.30$, and $766.10 \mathrm{~kg} / \mathrm{m}^{3}$ for Uyole-96, Kablanketi, and Wanja, respectively, whereas the apparent densities were determined as 1142,1158 , and $1327 \mathrm{~kg} / \mathrm{m}^{3}$, respectively, for the same types of beans. Results from the study showed that physical and mechanical properties for Uyole-96, Kablanketi, and Wanja differ significantly from other common beans cultivars cultivated in other countries. Data on physical and mechanical properties determined in this study establishes a convenient reference table for the mechanization and processing of Tanzanian common beans cultivars .
\end{abstract}

\section{Introduction}

Common bean also known as Phaseolus vulgaris L. is one among legume species extensively grown and consumed all over Tanzania. It is an herbaceous annual plant domesticated independently in ancient Mesoamerica and the Andes [1-3]. Different species of common beans are worldwide cultivated for their edible bean, popular as both dry and a green bean $[4,5]$. The common bean leaf is occasionally used as a leaf-vegetable and the straw is used for fodder. Botanically, the common beans are classified as a dicotyledonous group $[6,7]$. Common beans are relatively quite nutritionally rich, inexpensive sources of proteins, folic acid, dietary fibre, complex carbohydrates, and minerals and vitamins to millions of peoples in developed and developing countries [8-10]. Common beans are also termed as one of the best nonmeat sources of iron, providing $23 \%$ to $30 \%$ of daily recommended levels from single serving $[11,12]$.

In Tanzania, common beans are regularly cultivated as intercrops with other crops such as maize and spread widely across the Southern Highlands: the Northern, Western, and North-East parts $[7,10,13]$. In the Northern and Western parts, the common beans varieties grown are Tikyakuponza, Soya, Lyamungu-85, Canadian Wonder, Selian-94, Masai 


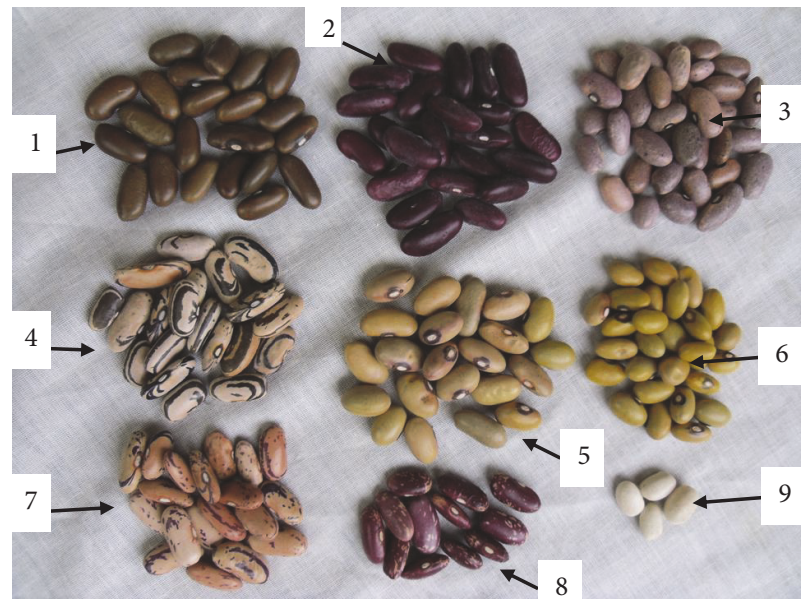

Figure 1: Beans types cultivated in the Southern Highlands Tanzania.

Red, Jesca, and Calima [7, 14, 15]. Diversities of common beans grown in the Southern Highland include Kablanketi, Wanja, Uyole-96, Uyole-94, TM Uyole, NRI, Masusu, Kasukanywele, Mwasipenjele, Kabanima, and Nyeupe (Small White) $[7,16]$. Physical appearances of almost all common beans cultivated in different parts of Tanzania are generally small and medium in size and shape and vary from one location to the other. Some common beans samples which are cultivated in the Southern Highlands of Tanzania are shown in Figure 1. From top left to right there are Masusu (\#1), Uyole-96 (\#2), Kablanketi (\#3), Kasukanywele (\#4), Wanja (\#5), Wanja-small (\#6), Mwasipenjele (\#7), and Kabanima (\#8).

Common beans as is the case for other legume species are characterized with the highest levels of variation in growth habit, physical appearance (size, shape, and colour), maturity, and adaptation $[2,17]$. Physical and mechanical properties are prerequisites in the design of suitable systems, machines, and structures for planting, harvesting, handling, processing, and storing of agro-products [18-20]. Understanding of these properties such as length, width, volume, friction behaviour, surface area, and weight is, for instance, significant in determining the design parameters for dehulling, sorting, and grading equipment, electrostatic separation of undesirable materials, linking mass transfer during different processes and quantification of bruise, abrasion, and damage in handling process. Common beans bulk density, angle of repose, and porosity properties have influence on air and mass flow resistance and therefore key parameters in the prediction of structural loads for storage structures [21-24].

The objective of this study was therefore to experimentally investigate some physical and mechanical properties of three common beans cultivars, namely, Uyole-96, Kablanketi, and Wanja, widely cultivated in the Southern Highlands of Tanzania. The choice of investigating these common beans cultivars was based on the facts that they have proved to have a high production rate, diseases tolerance, easy to cook, and short time to ripe and are very much marketable in Tanzania. The properties investigated included size (length and width), sphericity, weight, volume, coefficient of friction, angle of repose, moisture content, bulk, and apparent densities. Determined and then compared physical and mechanical properties establish a convenient reference table for the mechanization and processing of common beans cultivars cultivated in Tanzania.

\section{Materials and Methods}

2.1. Samples. Thirty dry beans seeds from each cultivars variety were randomly selected from four different market sources in Southern Highlands of Tanzania as study samples. A sample of 120 seeds were collected for Uyole-96, 120 for Kablanketi, and 120 for Wanja making a total of 360 for all three common beans cultivars varieties. These samples were thoroughly mixed for each cultivar and examined for determination of physical and mechanical properties. The selected dry bean seeds have been improved and developed by Agricultural Research Institute-Uyole (ARI-Uyole).

2.2. Determination of Moisture Content. Each group of Uyole-96, Kablanketi, and Wanja collected samples was weighed before oven drying by the use of an electronic weight of an accuracy of 0.01 grams. By the use of small trays, all samples were put in an oven for 18 hours at a temperature of $105^{\circ} \mathrm{C}$ as per ISO 665:2000 (determination of moisture content and volatile matter) and as reported in Wroniak et al. [25] and Yang et al. [26]. The moisture content was then calculated by using

$$
\text { Dry basis } m c_{d}=\left(\frac{w_{w}-w_{d}}{w_{d}}\right) 100
$$

where $w_{d}$ is weight of dried beans, $w_{w}$ is weight of wet bean (total weight), and $w c_{d}$ is dry moisture content (dry basis) in percentage.

\subsection{Physical and Mechanical Properties Experimental Setup}

2.3.1. Common Beans Physical Measurements. In determination of physical measurements of common beans, the followings were the tools and equipment employed:

(i) Weights of the samples were determined by using a precision electronic balance reading to an accuracy of 0.01gm.

(ii) To determine the average size of the seed, 100 seeds were randomly picked out of 120 seeds samples for Uyole-96 and their three principle dimensions (lengths, width, and thickness) were measured using a digital vernier caliper with an accuracy of $0.01 \mathrm{~mm}$ [27]. The same procedures were repeated for Kablanketi and Wanja, respectively. Figure 2 depicts common bean three principle dimensions.

(iii) Determination of the mean diameters (Da), geometric diameters $(\mathrm{Dg})$, and the sphericity $(\psi)$ was done by adopting Joshi et al. [28] and Tscheuschner [29] equations:

$$
D_{a}=\left(\frac{L+W+T}{3}\right)
$$




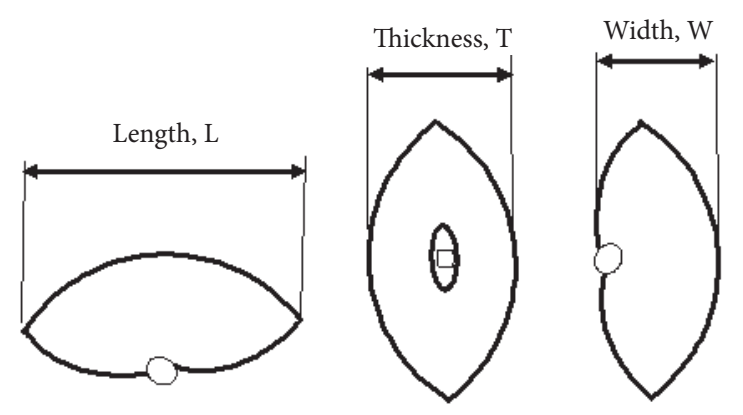

Figure 2: Common bean principal dimensions.

$$
\begin{aligned}
D_{g} & =(L W T)^{1 / 3} \\
\Psi & =\left(\frac{D_{g}}{L}\right) * 100
\end{aligned}
$$

(iv) Analysis of Variance (ANOVA) which is a statistical method was then used to compare and test differences between the results means using "ANOVA Single Factor" in one tail at $\mathrm{p} \leq 0.05$ or $95 \%$ significance.

2.3.2. Frictional Properties of Common Beans. Frictional properties of common bean seeds and pods were determined for the following sliding materials surfaces: plywood, plastic, aluminium, mild steel, and stainless steel using an apparatus setup as shown in Figure 3. With the apparatus arrangement set on horizontal plane, using a spirit level, a sample of ten seeds from each type of beans (Uyole-96, Kablanketi, and Wanja) was put on a sliding surface. The sliding surface was gradually raised until the first seed started to slide down. The surface angle was recorded at the point the seed started sliding. The test continued by further raising the surface until all the remaining seeds started sliding down, then the angle was recorded. Furthermore, another method was used by putting on the sliding surface one seed at a time. The sliding surface was gradually raised until the seed started to slide down, then the angle was recorded. The test continued for ten seeds in each type of beans. Another test similar to previous one was carried out using eighteen pods in each type (unthreshed beans). Pods of five seeds were put on the sliding surface one pod at a time gradually raising the surface until they started sliding down, then the angle was recorded. The coefficients of friction were calculated using (5) in which $\phi$ is the sliding angle (tilt angle) and $\mu$ is the static coefficient friction.

$$
\mu=\tan \phi
$$

2.3.3. Determination of Angle of Repose. Flow-ability of common beans was measured using the angle of repose that will be useful in material handling equipment. Known measures of two cylindrical diameter containers were used for an experiment, one being hollow put on the top of the closed one side. The common beans samples were filled in both containers.
The hollow container was slowly removed in the upwards direction to allow beans to flow down the closed container of the formation of conical shape $[30,31]$. The apex height was measured and the repose angle $(\phi)$ was calculated using trigonometry rule as given in (6) [32]. The same approach was previously applied in Bart-Plange and Baryeh [33] and BartPlange et al. [32] for category B cocoa beans and "obatanpa" maize variety, respectively. The experimental setup for measurements of repose angle is shown in Figures 4 and 5.

The angle of repose

$$
\phi=\tan ^{-1}\left(\frac{\text { Opposite }}{\text { Adjacent }}\right)=\tan ^{-1}\left(\frac{h}{r}\right)
$$

2.3.4. Bulk and Apparent Densities Determination. The average bulk densities for Uyole-96, Kablanketi, and Wanja beans seeds were determined using the standard test weight procedure as reported by Singh and Goswami [34]. Bulk density $\rho_{B}$ was determined by a known container volume, whose weight was measured and thereafter, common beans samples were filled in the container and their weight measured in $\mathrm{kg} / \mathrm{m}^{3}$. Computation of bulk density was done as per approach applied in Rao et al. [35] and Barbosa-Canovas et al. [36] using (7) where $m_{2}, m_{1}$, and $v_{c}$ are mass of known container, mass of known container with beans, and volume of known container, respectively.

$$
\rho_{B}=\frac{m_{2}-m_{1}}{v_{c}}
$$

Apparent density $\rho_{A}$ was determined by water displacement method as reported in Dutta et al. [37] of which a sample of dry common beans was weighed and put in a container filled with distilled water and then the displaced volume recorded. Determination of apparent density was done with precautions by enclosing the samples in a polythene and minimizing experimental time to ensure that the seeds did not absorb water as suggested in Kumagai et al. [38]. Computation of the apparent density was done using (8) where $m_{d}$, $v_{s}$, and $v_{h}$ are mass of common dry beans in grams, volume of water, and the saturated common beans in cubic centimetres and volume of water in cubic centimetres, respectively.

$$
\rho_{A p}=\left(\frac{m_{d}}{v_{s}-v_{h}}\right)
$$

\section{Results and Discussion}

3.1. Moisture Content. Common beans oven drying experiment for the determination of moisture content dry basis ( $\mathrm{db}$ ) is as shown in Figure 6. Results obtained in the determination of moisture contents experiment for Uyole-96, Kablanketi, and Wanja were $17.15 \% \mathrm{db} ., 13.92 \% \mathrm{db}$., and $14.64 \% \mathrm{db}$., respectively, as depicted in Table 1 . The results show that the moisture contents range was within those reported in Tavakoli et al. [39] for barley grains which was $7.34 \%$ to $21.58 \%$ $\mathrm{db}$ and that in Jones [11] which were between $8 \%$ to $30 \% \mathrm{db}$ and Mollazade et al. [40] for fennel seed (Foeniculum vulgare) which were between $7.78 \%$ to $21.67 \% \mathrm{db}$. 


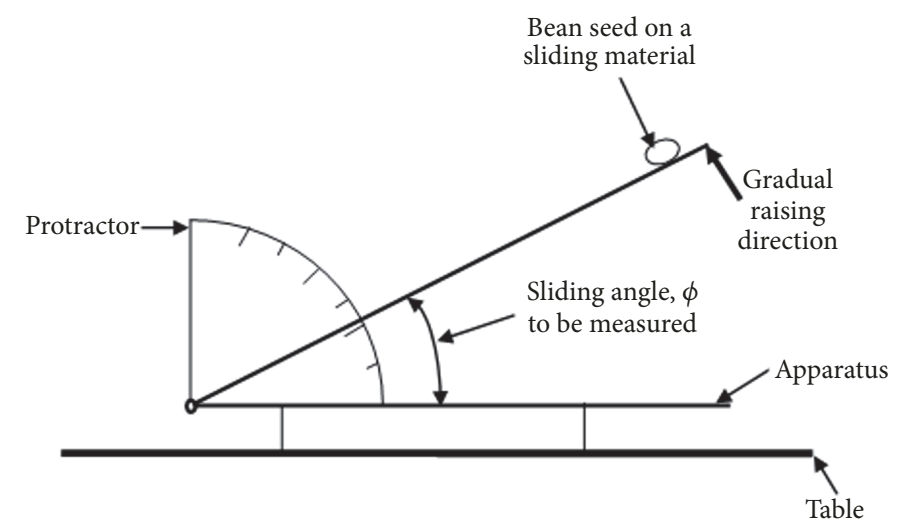

FIGURE 3: Setup for measuring common beans sliding angles.
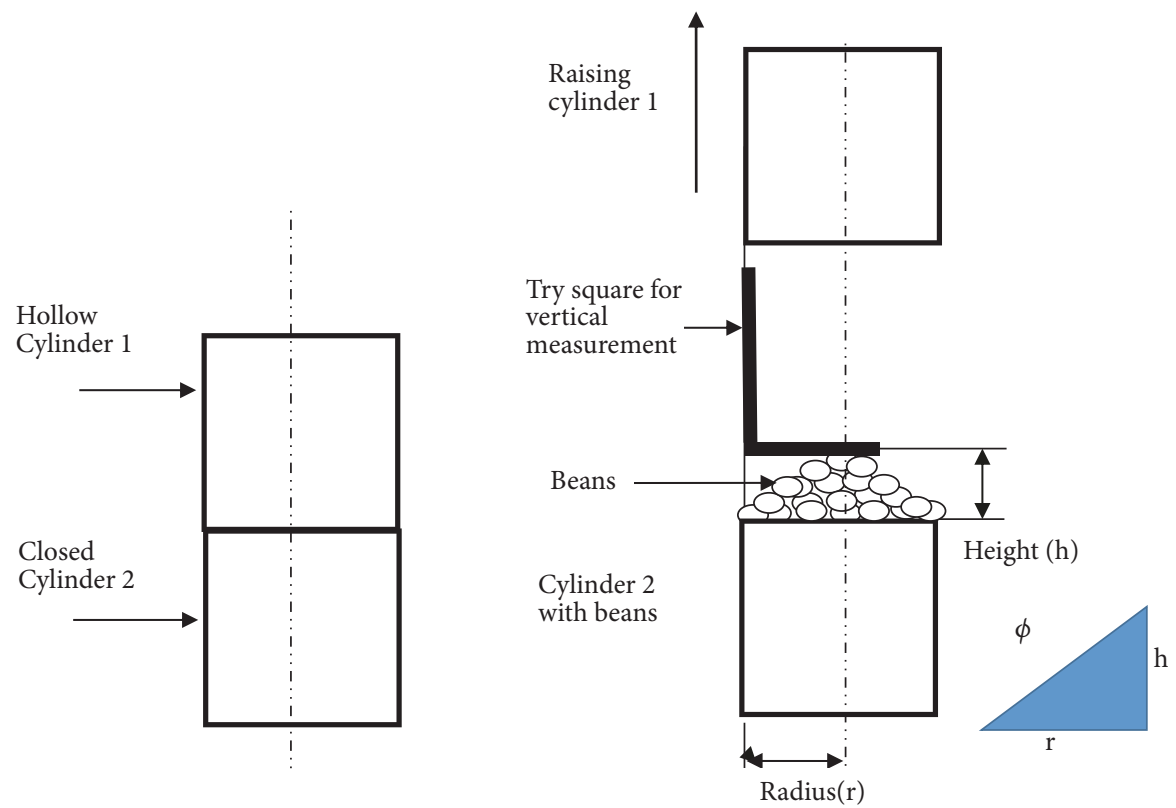

FIGURE 4: Experimental setup for repose angle measurements.

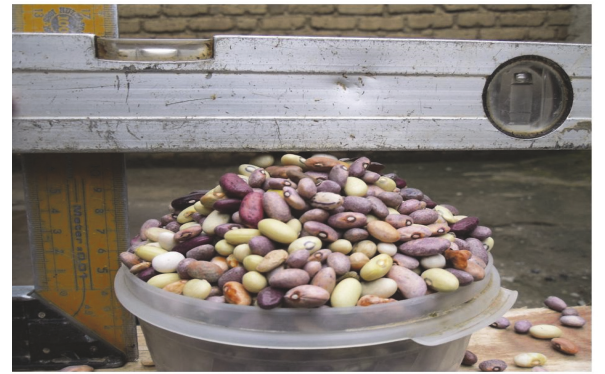

FiguRE 5: Beans in a vessel for angle of repose measurement.

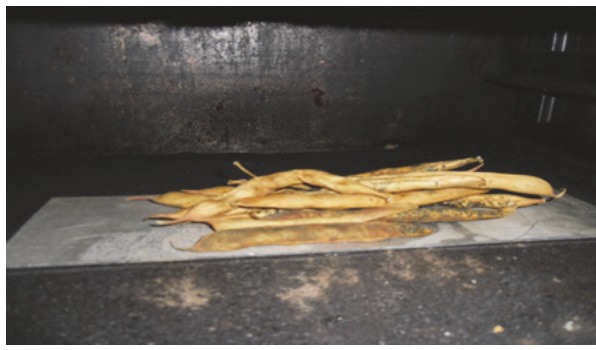

FIgURE 6: Common beans oven drying.
3.2. Common Beans Physical Properties. Physical properties measurements for Uyole-96, Kablanketi, and Wanja are presented in Table 2. In all measured values, the moisture contents were 17.15, 13.93, and 14.64 percent dry basis for
Uyole-96, Kablanketi, and Wanja, respectively. Average physical properties parameters were found to be 18.32, 13.71, and $15.06 \mathrm{~mm}$ in length; $8.97,8.21$, and $7.61 \mathrm{~mm}$ in width; 5.50 , 6.16 , and $5.93 \mathrm{~mm}$ in thickness, for Uyole-96, Kablanketi, and Wanja, respectively. 
TABLE 1: Moisture content experimental results.

\begin{tabular}{lc}
\hline Common bean type & Moisture content (\%) \\
\hline Uyole-96 (Red type) & 17.15 \\
\hline Kablanketi & 13.92 \\
\hline Wanja & 14.64 \\
\hline
\end{tabular}

TABLE 2: Common beans physical properties measurements.

\begin{tabular}{lcccc}
\hline Physical Properties & & Uyole-96 & Kablanketi & Wanja \\
\hline \multirow{3}{*}{ (1) Weight $(\mathrm{gm})$} & Min & 0.45 & 0.23 & 0.34 \\
& Max & 0.73 & 0.69 & 0.71 \\
& Average & 0.62 & 0.47 & 0.50 \\
\hline \multirow{3}{*}{ (2) Length $(\mathrm{mm})$} & Min & 15.25 & 11.39 & 13.16 \\
& Max & 19.96 & 16.75 & 16.98 \\
& Average & 18.32 & 13.71 & 15.06 \\
\hline \multirow{3}{*}{ (3) Width $(\mathrm{mm})$} & Min & 8.15 & 6.86 & 6.55 \\
& Max & 10.92 & 9.56 & 9.17 \\
& Average & 8.97 & 8.21 & 7.61 \\
\hline \multirow{3}{*}{ (4) Thickness $(\mathrm{mm})$} & Min & 4.68 & 4.46 & 4.80 \\
& Max & 6.02 & 7.60 & 7.05 \\
& Average & 5.50 & 6.16 & 5.93 \\
\hline \multirow{3}{*}{ (5) Mean diameter $\left(\mathrm{D}_{\mathrm{a}}\right)$} & Min & 9.80 & 7.57 & 8.69 \\
& Max & 11.96 & 10.76 & 11.01 \\
& Av & 10.93 & 9.35 & 9.55 \\
\hline \multirow{4}{*}{ (6) Geometric Mean $\left(\mathrm{D}_{\mathrm{g}}\right)$} & Max & 10.60 & 10.16 & 10.25 \\
& Av & 9.66 & 8.33 & 8.80 \\
\hline \multirow{3}{*}{ (7) Sphericity $(\psi)$} & Min & 50 & 57 & 52 \\
& Max & 59 & 70 & 63 \\
& Av & 53 & 64 & 58 \\
\hline
\end{tabular}

TABle 3: Physical measurements comparison using ANOVA.

\begin{tabular}{lcc}
\hline Physical properties & Comparison beans & $\boldsymbol{p}$-value \\
\hline \multirow{3}{*}{ Weight } & Uyole-96 vs Kablanketi & $1.83 \mathrm{E}-07$ \\
& Kablanketi vs Wanja & 0.399 \\
& Uyole-96 vs Wanja & $1.47 \mathrm{E}-07$ \\
\hline \multirow{3}{*}{ Length } & Uyole-96 vs Kablanketi & $2.087 \mathrm{E}-23$ \\
& Kablanketi vs Wanja & $1.054 \mathrm{E}-05$ \\
& Uyole-96 vs Wanja & $3.72 \mathrm{E}-18$ \\
\hline \multirow{3}{*}{ Width } & Uyole-96 vs Kablanketi & $3.23 \mathrm{E}-05$ \\
& Kablanketi vs Wanja & 0.0029 \\
& Uyole-96 vs Wanja & $4.23 \mathrm{E}-09$ \\
\hline \multirow{3}{*}{ Thickness } & Uyole-96 vs Kablanketi & $3.22 \mathrm{E}-0.5$ \\
& Kablanketi vs Wanja & 0.0029 \\
& Uyole-96 vs Wanja & $4.23 \mathrm{E}-09$ \\
\hline
\end{tabular}

Comparisons in terms of lengths indicate that Uyole-96 seeds are longer than Wanja and Kablanketi, respectively, and larger than common beans cultivars Elkoca-05 examined in Ozturk and Kara [41] which were 12.48, 7.92, and $5.00 \mathrm{~mm}$ for length, width, and thickness, respectively, and that of barbunia bean seed [42] which were $16.68 \mathrm{~mm}, 9.36 \mathrm{~mm}$, and $7.51 \mathrm{~mm}$, at a moisture content of $18.33 \% \mathrm{db}$. The physical properties measurements in terms of weights for selected samples reveal that Uyole-96 was heavier followed by Wanja and Kablanketi.

The weights ranges were less than those analysed in America and reported in FAOSTAT [43] which were $1.1 \mathrm{gm} / \mathrm{seed}, 1.1$ to $1.7 \mathrm{gm} / \mathrm{seed}$, and $1.7 \mathrm{gm} / \mathrm{seed}$ for small, medium, and large sizes, respectively. The findings show that the average mean diameter $\left(D_{a}\right)$ was found to be 10.93, 9.35, and $9.55 \mathrm{~mm}$ for Uyole-96, Kablanketi, and Wanja, respectively. The geometric mean $\left(\mathrm{D}_{\mathrm{g}}\right)$ was $9.66,8.35$, and $8.80 \mathrm{~mm}$ for the same types of beans. The sphericity was found to be 53,64 , and $58 \%$ for Uyole-96, Kablanketi, and Wanja, respectively. In all measured values, the moisture contents were $17.15,13.93$, and 14.64 percent $\mathrm{db}$ for the same types of beans. Based on the summary of results presented in Table 1 , the average mean and geometric mean diameters of Uyole96 were bigger than other types of beans analysed while the sphericity for Kablanketi was bigger than that of Wanja and Uyole-96. The obtained results were then compared with that of Elkoca-05 as examined in Ozturk and Kara [41] and found that they were larger in mean diameter and geometric mean. However, Elkoca-05 had the same results as Kablanketi for sphericity dimensions. The results for Elkoca- 05 were 8.47 to $9.15 \mathrm{~mm}, 7.90$ to $8.56 \mathrm{~mm}$, and 0.64 (64\%) for mean diameter, geometric mean, and sphericity, respectively, as the moisture content increased from $7.82 \%$ to $19.39 \% \mathrm{db}$.

Using "ANOVA Single Factor" in one tail at $p \leq 0.05$ or 95\% significance value as shown in Table 3, the presented data indicate that there was a high significance difference for all types of beans compared in weight, length, width, and thickness, except for weights of Kablanketi and Wanja ( $\mathrm{p}$-value $=0.399)$. Correspondingly, there is a significant difference if physical properties for Uyole-96, Kablanketi, and Wanja are equated with common beans grown in other countries in all dimensions.

3.3. Frictional Properties of Common Bean. Frictional properties of common beans were determined using different sliding surface materials having a minimum angle with its coefficient of friction for a single seed and a maximum angle with its coefficient of friction for the remaining seeds as depicted in Table 4. Likewise, maximum coefficients of friction for different sliding surfaces materials, one seed at a time for the same types of common beans is presented in Table 5. Uyole96 exhibited high coefficients of friction in all materials for the two types of tests, followed by Kablanketi and Wanja. The coefficients of friction of beans for all tests were nearly the same values in the same material. However, stainless steel material exhibited low coefficients of friction in all testes followed by aluminium and mild steel. The coefficients of friction results for the same materials were greater than those analysed for Elkoca-05 [41].

The results for coefficients of friction of unthreshed beans pods are as presented in Table 6. The average coefficients of friction for the bean pods on plywood, plastic, mild steel aluminium, and stainless steel surfaces were $0.65,0.61$, 
TABLE 4: Frictional properties for dissimilar sliding surface materials.

\begin{tabular}{|c|c|c|c|c|c|}
\hline \multirow{2}{*}{ Surface material } & \multirow{2}{*}{ Common beans type } & \multicolumn{2}{|c|}{ Angle in degrees } & \multicolumn{2}{|c|}{ Coefficient of friction } \\
\hline & & Single Seed & Remaining Seeds & Single Seed & Remaining Seeds \\
\hline \multirow{3}{*}{ Ply Wood } & Uyole-96 & 24 & 30 & 0.45 & 0.58 \\
\hline & Kablanketi & 23 & 29 & 0.42 & 0.55 \\
\hline & Wanja & 20 & 27 & 0.36 & 0.51 \\
\hline \multirow{3}{*}{ Plastic } & Uyole-96 & 20 & 26 & 0.36 & 0.49 \\
\hline & Kablanketi & 18 & 24 & 0.33 & 0.46 \\
\hline & Wanja & 18 & 23 & 0.33 & 0.42 \\
\hline \multirow{3}{*}{ Mild Steel } & Uyole-96 & 18 & 22 & 0.33 & 0.40 \\
\hline & Kablanketi & 17 & 20 & 0.31 & 0.36 \\
\hline & Wanja & 17 & 20 & 0.31 & 0.36 \\
\hline \multirow{3}{*}{ Aluminium } & Uyole-96 & 17 & 21 & 0.31 & 0.38 \\
\hline & Kablanketi & 16 & 19 & 0.29 & 0.34 \\
\hline & Wanja & 16 & 19 & 0.29 & 0.34 \\
\hline \multirow{3}{*}{ Stainless steel } & Uyole-96 & 16 & 20 & 0.29 & 0.36 \\
\hline & Kablanketi & 15 & 19 & 0.29 & 0.34 \\
\hline & Wanja & 15 & 18 & 0.27 & 0.33 \\
\hline
\end{tabular}

TABle 5: Coefficients of friction on dissimilar sliding material surfaces (one seed at a time).

\begin{tabular}{lcccc}
\hline Material & Beans Type & Minimum & Maximum & Average \\
\hline \multirow{3}{*}{ Plywood } & Uyole-96 & 0.45 & 0.58 & 0.51 \\
& Kablanketi & 0.42 & 0.55 & 0.49 \\
& Wanja & 0.42 & 0.49 & 0.46 \\
\hline \multirow{3}{*}{ Plastic } & Uyole-96 & 0.36 & 0.49 & 0.42 \\
& Kablanketi & 0.32 & 0.45 & 0.37 \\
& Wanja & 0.32 & 0.42 & 0.37 \\
\hline \multirow{3}{*}{ Aluminium } & Uyole-96 & 0.31 & 0.38 & 0.35 \\
& Kablanketi & 0.21 & 0.36 & 0.31 \\
& Wanja & 0.27 & 0.36 & 0.32 \\
\hline \multirow{3}{*}{ Mild Steel } & Uyole-96 & 0.31 & 0.38 & 0.34 \\
& Kablanketi & 0.31 & 0.36 & 0.33 \\
& Wanja & 0.31 & 0.36 & 0.33 \\
\hline \multirow{3}{*}{ Stainless Steel } & Kablanketi & 0.27 & 0.34 & 0.30 \\
& Wanja & 0.25 & 0.32 & 0.29 \\
\hline
\end{tabular}

$0.59,0.52$, and 0.48 , respectively. These results show that the coefficients of friction for unthreshed beans are higher than for threshed ones.

3.4. The Angle of Repose. Laboratory setup for measurements of repose angle which is a physical measurement for common beans is depicted in Figure 6 whereas Table 7 presents the results found for repose angles which were 40, 36, and 35 degrees for Uyole-96, Kablanketi, and Wanja. The results were within those reported in Bennett et al. [44] for calculating bushels, where the repose angles were between 25 to 45 degrees for beans in different moisture contents.

3.5. Densities. The results for bulk and apparent densities are presented in the following sections.
3.5.1. Bulk Density. The results obtained in the measurements of common beans weight for apparent density analysis were $709.27,686.30$, and $766.10 \mathrm{~kg} / \mathrm{m}^{3}$ for Uyole-96, Kablanketi, and Wanja, respectively, as depicted in Table 8 . The bulk densities for Uyole-96 and Kablanketi were less than those reported in FAOSTAT [43] which were 760, 750, and $740 \mathrm{~kg} / \mathrm{m}^{3}$ for navy, mung, and cowpea, respectively. The bulk density experimental results for Wanja were shown to be more than that of Uyole-96 and Kablanketi, respectively.

3.5.2. Apparent Density. Table 9 presents the data used for determining the apparent density and the results obtained. The common beans apparent densities for Uyole-96, Kablanketi, and Wanja were 1142,1158 , and $1327 \mathrm{~kg} / \mathrm{m}^{3}$, respectively. The apparent densities for Uyole-96 and Kablanketi were less than that of Kantar-05 as reported in Berdaftar'Kantar et al. [45] which were ranging between 1206.55 and $1269.37 \mathrm{~kg} / \mathrm{m}^{3}$.

\section{Conclusion}

Physical and mechanical properties are of vital importance in many challenges associated with the design of machines and behaviour analysis of various products during agriculture processing operations. Despite Phaseolus vulgaris L. important roles in human diet, there is a lack of information on the physical and mechanical properties of common beans cultivars cultivated in Tanzania. This study was therefore focused on experimental determination of physical and mechanical properties for Uyole-96, Kablanketi, and Wanja, which are among many common beans cultivars grown in the Southern Highlands of Tanzania. Results from this study showed that the maximum length was 1.6 , width 1.4 , and thickness 1.2 times more than those found in common beans cultivars cultivated in Middle East and America. The maximum seed weight comparison showed that the common beans cultivars grown in Tanzania are lighter than those grown in other countries. Correspondingly, the apparent density of Wanja 
TABLE 6: Coefficients of friction for un-threshed beans pods.

\begin{tabular}{lcccccc}
\hline \multirow{2}{*}{ /N } & Material & \multicolumn{2}{c}{ Angle (degrees) } & \multicolumn{2}{c}{ Coefficient of friction } \\
& & Min & Max & Min & Max & Average \\
\hline 1 & Plywood & 30 & 36 & 0.58 & 0.74 & 0.65 \\
\hline 2 & Plastic & 29 & 34 & 0.55 & 0.67 & 0.61 \\
\hline 3 & Mild Steel & 28 & 33 & 0.53 & 0.65 & 0.59 \\
\hline 4 & Aluminium & 25 & 30 & 0.42 & 0.53 & 0.52 \\
\hline 5 & Stainless Steel & 23 & 28 & & 0.48 \\
\hline
\end{tabular}

TABLe 7: Angle of repose results.

\begin{tabular}{lr}
\hline Common bean type & Repose angle (degrees) \\
\hline Uyole-96 (Red type) & 40 \\
\hline Kablanketi & 36 \\
\hline Wanja & 35 \\
\hline
\end{tabular}

TABLE 8: Common beans bulk density results.

\begin{tabular}{lcccc}
\hline Type of beans & Jug volume $(\mathbf{m l})$ & Jug weight $(\mathbf{g m})$ & $\begin{array}{c}\text { Common bean } \\
\text { weight }(\mathbf{g m})\end{array}$ & $\begin{array}{c}\text { Bulk density } \\
\left(\mathbf{k g} / \mathbf{m}^{\mathbf{3}}\right)\end{array}$ \\
\hline Uyole-96 & 50 & 112.6930 & 148.1565 & 709.27 \\
Kablanketi & 50 & 112.6930 & 147.0085 & 686.30 \\
Wanja & 50 & 112.6930 & 150.9980 & 766.10 \\
\hline
\end{tabular}

TABLE 9: Common beans apparent density analysis results.

\begin{tabular}{lcccc}
\hline Common bean type & Jug volume $(\mathbf{m l})$ & Total volume $(\mathbf{m l})$ & $\begin{array}{c}\text { Common bean } \\
\text { weight }(\mathbf{g m})\end{array}$ & $\begin{array}{c}\text { Apparent density } \\
(\mathbf{g m} / \mathbf{c c})\end{array}$ \\
\hline Uyole-96 & 50 & 64 & 15.9936 & 1.142 \\
Kablanketi & 50 & 64 & 15.0495 & 1.158 \\
Wanja & 50 & 64 & 15.9223 & 1.327 \\
\hline
\end{tabular}

was 1.16 times more than that of Uyole-96 and was 1.14 times more than of Kablanketi whereas coefficient of bean pods was higher than that of bean seeds. However, the bulk and apparent densities of the experimental results showed similarities with common beans cultivars grown in other countries. Based on this study findings, Uyole-96, Kablanketi, and Wanja physical and mechanical properties are significantly different from common beans cultivars cultivated in other countries. Physical and mechanical properties determined for Uyole-96, Kablanketi, and Wanja establish a convenient reference table for the mechanization and processing of Tanzanian common beans cultivars.

\section{Data Availability}

The data used to support the findings of this study are available from the corresponding author upon request.

\section{Conflicts of Interest}

The authors declare that they have no conflicts of interest.

\section{References}

[1] L. Kaplan, "What is the origin of the common bean?" Economic Botany, vol. 35, no. 2, pp. 240-254, 1981.

[2] S. P. Singh, "Patterns of variation in cultivated common bean (Phaseolus vulgaris, Fabaceae)," Economic Botany, vol. 43, no. 1, pp. 39-57, 1989.

[3] M. Kwak, O. Toro, D. G. Debouck, and P. Gepts, "Multiple origins of the determinate growth habit in domesticated common bean (Phaseolus vulgaris)," Annals of Botany, vol. 110, no. 8, pp. 1573-1580, 2012.

[4] I. Hayat, A. Ahmad, T. Masud, A. Ahmed, and S. Bashir, "Nutritional and health perspectives of beans (Phaseolus vulgaris L.): an overview," Critical Reviews in Food Science and Nutrition, vol. 54, no. 5, pp. 580-592, 2014.

[5] M. Beatrice, N. Susan, N. Paul et al., "Viruses infecting common bean (Phaseolus vulgaris L.) in Tanzania: A review on molecular characterization, detection and disease management options," African Journal of Agricultural Research, vol. 12, no. 18, pp. 1486$1500,2017$.

[6] M. A. Uebersax, Dry edible beans: indigenous staple and healthy cuisine, M. A. Uebersax, Ed., Forum on Public Policy, 2006. 
[7] E. Katungi, A. Farrow, J. Chianu, L. Sperling, and S. Beebe, "Common bean in Eastern and Southern Africa: a situation and outlook analysis," vol. 61, 2009.

[8] D. Pachico, "The demand for bean technology," in Trends in CIAT commodities, pp. 60-73, The demand for bean technology. Trends in CIAT commodities, 60-73, 1993.

[9] Z.-U. Rehman, A. M. Salariya, and S. I. Zafar, "Effect of processing on available carbohydrate content and starch digestibility of kidney beans (Phaseolus vulgaris L.)," Food Chemistry, vol. 73, no. 3, pp. 351-355, 2001.

[10] A. J. Cortés, F. A. Monserrate, J. Ramírez-Villegas, S. Madriñán, and M. W. Blair, "Drought Tolerance in Wild Plant Populations: The Case of Common Beans (Phaseolus vulgaris L.)," PLoS ONE, vol. 8, no. 5, Article ID e62898, 2013.

[11] A. Jones, Phaseolus bean: Post-harvest operations, D. Mejia and B. Lewis, Eds., AGSI/FAO: Centro Internacional de Agricultura Tropical (CIAT), 1999.

[12] E. A. Shimelis and S. K. Rakshit, "Proximate composition and physico-chemical properties of improved dry bean (Phaseolus vulgaris L.) varieties grown in Ethiopia," LWT-Food Science and Technology, vol. 38, no. 4, pp. 331-338, 2005.

[13] N. Fivawo and S. Msolla, "The diversity of common bean landraces in Tanzania," TaJONAS: Tanzania Journal of Natural and Applied Sciences, vol. 2, no. 1, pp. 337-351, 2012.

[14] S. Ferris and E. Kaganzi, "Evaluating marketing opportunities for haricot beans in Ethiopia".

[15] C. Larochelle, E. Katungi, and Z. Cheng, "Pulse consumption and demand by different population subgroups in Uganda and Tanzania," 2017.

[16] N. C. Fivawo and S. N. Msolla, "The Diversity of Common Bean Landraces in Tanzania. Phase II: Multi-Location Trial," TaJONAS: Tanzania Journal of Natural and Applied Sciences, vol. 3, no. 1, pp. 500-516, 2012.

[17] P. Gepts and D. Debouck, "Origin, domestication, and evolution of the common bean (Phaseolus vulgaris L.)," Common beans: research for crop improvement, vol. 7, p. 53, 1991.

[18] E. Mirzaee, S. Rafiee, A. Keyhani, and Z. E. Djom-Eh, "Physical properties of apricot to characterize best post harvesting options," Australian Journal of Crop Science, vol. 3, no. 2, pp. 95100, 2009.

[19] A. Ganachari, K. Thangavel, S. Ali, U. Nidoni, and A. Ananthacharya, "Physical properties of Aonla fruit relevant to the design of processing equipments. International Journal of Engineering," International Journal of Engineering, Science and Technology, vol. 12, pp. 7562-7566, 2010.

[20] A. Khadivi-Khub, "Analysis of Some Technological and Physical Characters of Mandarin (Citrus reticulata) Fruit in Iran," ISRN Agronomy, vol. 2013, Article ID 891792, 4 pages, 2013.

[21] N. Kotwaliwale, G. H. Brusewitz, and P. R. Weckler, "Physical characteristics of pecan components: Effect of cultivar and relative humidity," Transactions of the ASAE, vol. 47, no. 1, pp. 227-231, 2004.

[22] R. Luther, D. A. Suter, and G. H. Brusewitz, "Physical properties of food materials," 2004.

[23] P. Nesvadba, M. Houška, W. Wolf et al., "Database of physical properties of agro-food materials," Journal of Food Engineering, vol. 61, no. 4, pp. 497-503, 2004.

[24] E. Altuntas and H. Demirtola, "Effect of moisture content on physical properties of some grain legume seeds," New Zealand Journal of Crop and Horticultural Science, vol. 35, no. 4, pp. 423433, 2007.
[25] M. Wroniak, A. Rekas, A. Siger, and M. Janowicz, "Microwave pretreatment effects on the changes in seeds microstructure, chemical composition and oxidative stability of rapeseed oil," LWT-Food Science and Technology, vol. 68, pp. 634-641, 2016.

[26] M. Yang, F. Huang, C. Liu, C. Zheng, Q. Zhou, and H. Wang, "Influence of Microwave Treatment of Rapeseed on Minor Components Content and Oxidative Stability of Oil," Food and Bioprocess Technology, vol. 6, no. 11, pp. 3206-3216, 2013.

[27] E. Altuntaş, E. Özgöz, and Ö. F. Taşer, "Some physical properties of fenugreek (Trigonella foenum-graceum L.) seeds," Journal of Food Engineering, vol. 71, no. 1, pp. 37-43, 2005.

[28] D. C. Joshi, S. K. Das, and R. K. Mukherjee, "Physical properties of pumpkin seeds," Journal of Agricultural Engineering Research, vol. 54, no. 3, pp. 219-229, 1993.

[29] H. D. Tscheuschner, NN Mohsenin: Physical Properties of Plant and Animal Materials. Structure, Physical Characteristics and Mechanical Properties. 2. Aufl. 891 Seiten, zahlr. Abb. und Tab, vol. 31, Gordon and Breach Science Publishers, New York, NY, USA, 1987.

[30] A. Koocheki, S. M. A. Razavi, E. Milani et al., "Physical properties of watermelon seed as a function of moisture content and variety," International Agrophysics, vol. 21, no. 4, pp. 349-359, 2007.

[31] A. Bart-Plange, K. A. Dzisi, and J. Ampah, "Effect of drying on selected physical properties of, Asontem cowpea variety," ISRN Agronomy, 2012.

[32] A. Bart-Plange, A. Addo, and K. Dzisi, "The effects of rewetting and drying on selected physical properties of Obatanpamaize variety," Journal of the Ghana Institution of Engineers, vol. 3, no. 1, pp. 12-15, 2005.

[33] A. Bart-Plange and E. A. Baryeh, "The physical properties of Category B cocoa beans," Journal of Food Engineering, vol. 60, no. 3, pp. 219-227, 2003.

[34] K. K. Singh and T. K. Goswami, "Physical properties of cumin seed," Journal of Agricultural and Engineering Research, vol. 64, no. 2, pp. 93-98, 1996.

[35] M. A. Rao, S. S. Rizvi, A. K. Datta, and J. Ahmed, "Engineering properties of foods," CRC, p. presspp, 2014.

[36] G. Barbosa-Canovas, P. Juliano, and M. Peleg, "Engineering properties of foods, Food engineering: Encyclopedia of life support systems," EOLSS Oxford, pp. 39-70, 2009.

[37] S. K. Dutta, V. K. Nema, and R. K. Bhardwaj, "Physical properties of gram," Journal of Agricultural Engineering Research, vol. 39, no. 4, pp. 259-268, 1988.

[38] H. Kumagai, T. Inukai, T. Fujii, and T. Yano, Mechanical Properties of Foods. Food Hydrocolloids: Structures, Properties, and Functions, vol. 251, 2012.

[39] H. Tavakoli, S. Mohtasebi, A. Rajabipour, and M. Tavakoli, "Effects of moisture content, loading rate, and grain orientation on fracture resistance of barley grain," Research in Agricultural Engineering, vol. 55, no. No. 3, pp. 85-93, 2009.

[40] K. Mollazade, H. Ahmadi, J. Khorshidi, S. S. Mohtasebi, and A. Rajabipour, "Some Physical and Mechanical Properties of Fennel Seed (Foeniculum vulgare)," Journal of Agricultural Science, vol. 1, no. 1, 2009.

[41] I. Ozturk, M. Kara, E. Elkoca, and S. Ercisli, "Physico-chemical grain properties of new common bean cv. 'Elkoca-05', Scientific Research and Essays, vol. 4, no. 2, pp. 088-093, 2008.

[42] M. Cetin, "Physical properties of barbunia bean (Phaseolus vulgaris L. cv. 'Barbunia') seed," Journal of Food Engineering, vol. 80, no. 1, pp. 353-358, 2007. 
[43] FAOSTAT, "Food and Agricultural Organization statistical database," http://www.fao.org/faostat/en/\#data, 2017.

[44] J. M. Bennett, D. R. Hicks, and S. L. Naeve, The Minnesota Soybean Field Book, Extension Service, MN., University of Minnesota, 1999.

[45] B. Berdaftar'Kantar, I. Ozturk, M. Kara, and S. Ercisli, "Physical and chemical grain properties of new registered common bean cv.Kantar-05," Sains Malaysiana, vol. 39, no. 5, pp. 725-730, 2010. 


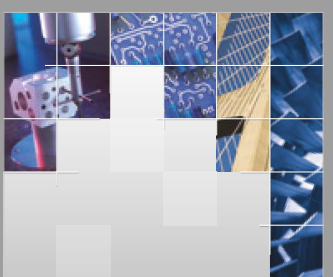

\section{Enfincering}
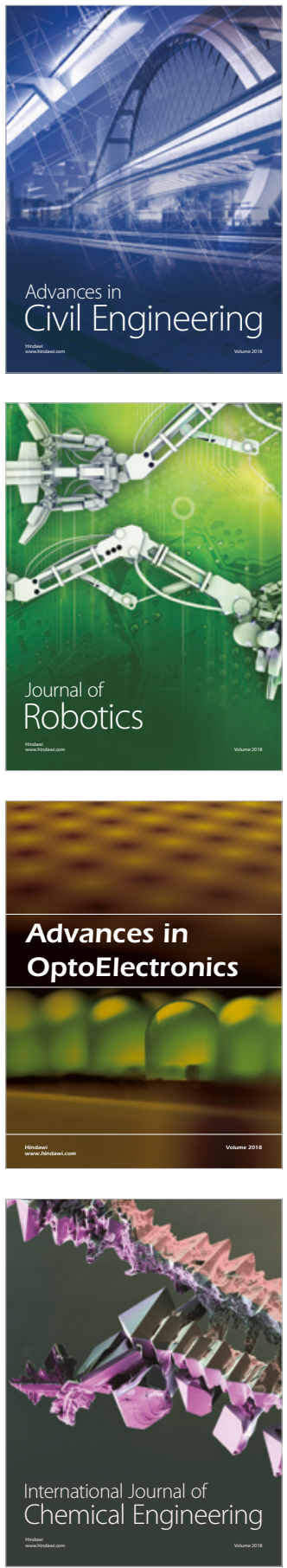

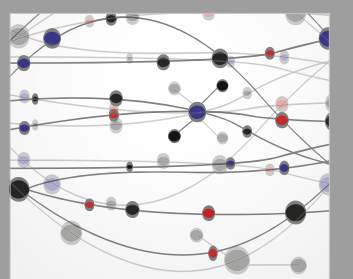

\section{Rotating \\ Machinery}

The Scientific World Journal

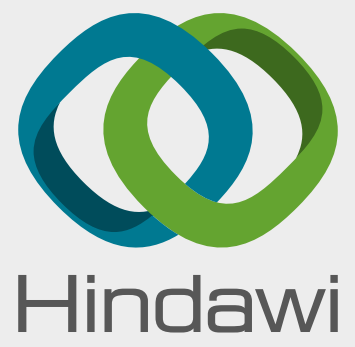

Submit your manuscripts at

www.hindawi.com
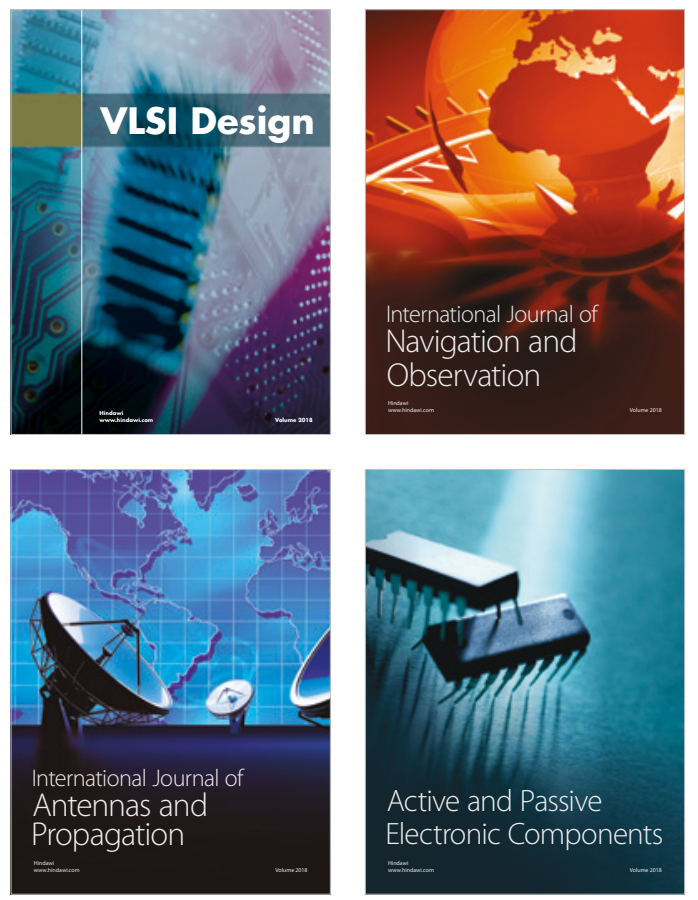
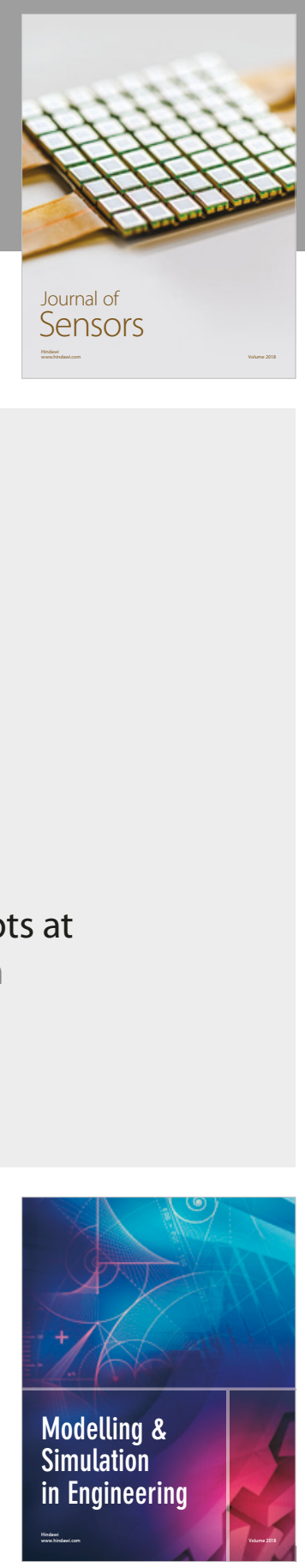

\section{Advances \\ Multimedia}
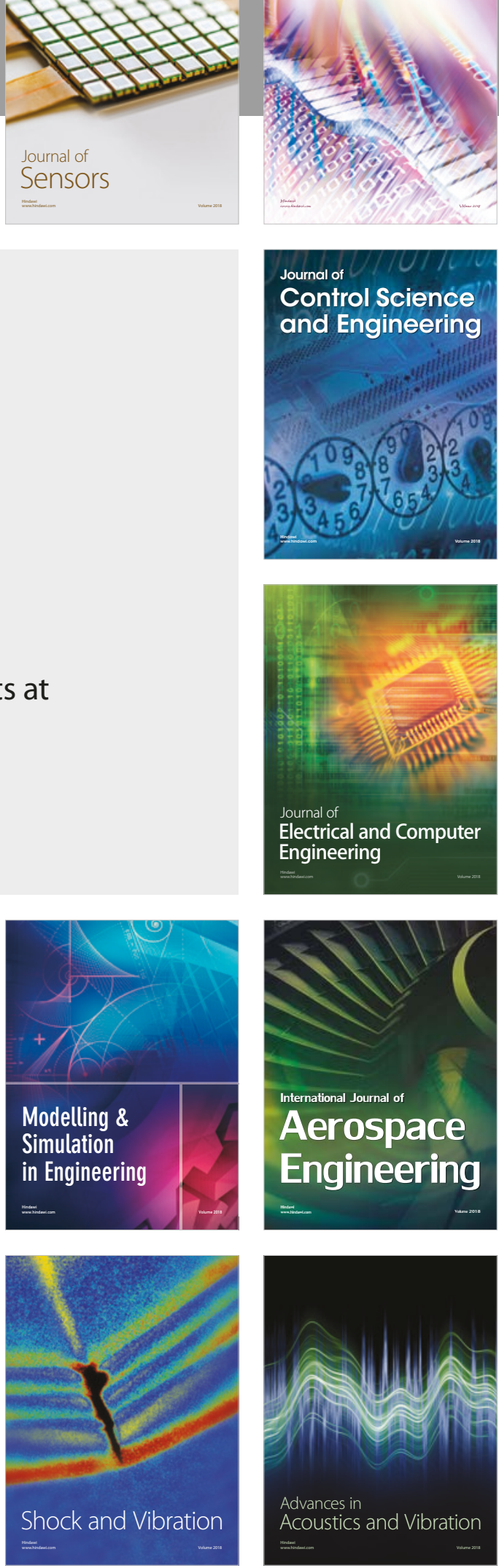